\title{
Early Application of Pedicled Omentum to the Acutely Traumatised Spinal Cord
}

\author{
Harry S. Goldsmith, M.D., ${ }^{1}$ Earl Steward ${ }^{2}$ and Serge Duckett, M.D. ${ }^{3}$ \\ ${ }^{1}$ Professor of Surgery, Adjunct Professor of Neurosurgery, ${ }^{2}$ Boston University School \\ of Medicine and ${ }^{3}$ Professor of Neuropathology, Fefferson Medical College, Boston \\ 02118, Massachusetts, U.S.A.
}

\begin{abstract}
Summary
Placement of the intact omentum upon a recently traumatised spinal cord was found to be effective in lessening motor and neuroelectrical dysfunction in a group of cats. It was theorised that the beneficial effect of omental transposition was due to the establishment of a dynamic equilibrium between production of vasogenic oedema from the injured cord and its absorption through omental pathways. Removing vasogenic oedema at the omental/spinal cord interface is hypothesised to stabilise a rising tissue pressure within the cord during the acute phase of injury and at a later date to decrease scar formation at the injury site.
\end{abstract}

Key words: Spinal cord injury; Intact omental transposition; Motor and neuroelectrical activity.

Previous reports from our laboratory have shown that placing the intact omentum directly upon the normal and traumatized spinal cord allows for the development of blood vessels (Goldsmith et al., 1975) and the absorption of vasogenic oedema fluid (Goldsmith et al., 1983) at the omental-spinal cord interface.

The purpose of this study was to learn the effect of early placement of the pedicled omentum on a recently traumatised cat spinal cord as measured by subsequent motor and neuroelectrical activity of the hind limbs.

\section{Materials and methods}

Adult female cats weighing $3 \cdot 0-3.5 \mathrm{~kg}$ were used in this study. Ketalar (33 $\mathrm{mgm} / \mathrm{kg}$ ) was given intramuscularly for anaesthesia with additional amounts (12-25 mgm) of the agent being administered when necessary during the

Address: H. S. Goldsmith, M.D., University Hospital, 75 East Newton Street, Boston, MA 02118.

This study was supported by the American Paralysis Association and the Surgical Rehabilitation Foundation of Boston. 
operation. All animals were placed in a prone position and subjected to a T-9 laminectomy. After removing epidural fat, the spinal cord was injured at the laminectomy site using the technique of Allen (Allen, 1911) in which a weight is dropped onto the intact dura through a minimally frictionless Teflon tube having multiple perforations. In order to eliminate reverberation of the impactor on the spinal cord at the time of injury, a fairly heavy weight (83 gm) was dropped from a relatively short height $(5.5 \mathrm{~cm})$ causing a $456 \mathrm{gm} / \mathrm{cm}$ injury. All cats received $1 \mathrm{cc}$ of Combiotic $(200,000 \mathrm{U}$ procaine penicillin $\mathrm{G}$ and 250 mgm Dihydrostreptomycin sulphate) immediately prior to spinal cord injury and daily thereafter for 5 days.

All cats in this study were carefully evaluated 30 days after injury in terms of their ability to walk according to a modified Tarlov neurological classification (Tarlov, 1957) (Table 1). Additionally, all cats had somatosensory evoked potential(SEP) performed on all extremities 30 days after injury which was done by stimulating the median nerve of the front limbs and the sciatic nerve of the back limbs with the resulting SEPs being recorded at the cortical level.

Table 1 Modified Tarlov Classification

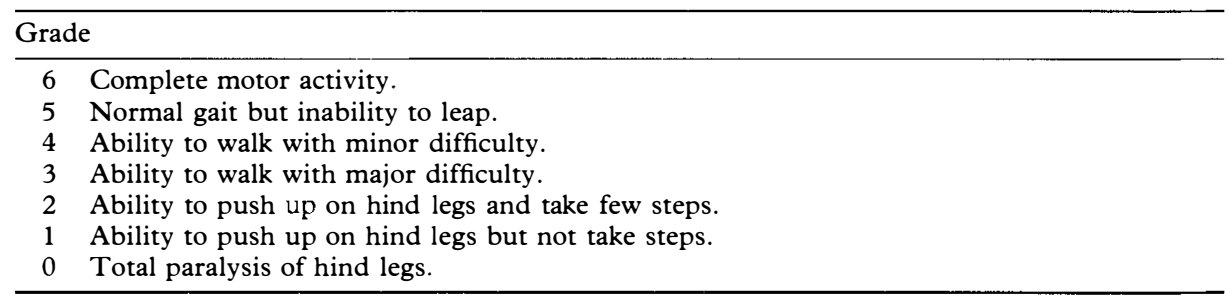

Cats who had early omental placement ( 3 hours after spinal cord injury) were sacrificed 30 days following injury. Another group of cats who had late omental placement ( 6 and 8 hours, respectively, after cord injury) were evaluated 30 days after injury, but they were not sacrificed until 45 days after trauma in order to learn if this added time before death would have any effect on their final motor and neuroelectrical status.

\section{Control animals}

Eleven cats were subjected to our standard spinal cord injury. Immediately after trauma, the back muscles overlying the dura and spinal cord were loosely approximated followed by skin closure. Exactly three hours after cord injury, the skin and back muscles of the cats were separated, and the dura and arachnoid overlying the injured spinal cord were removed following which cerebrospinal fluid drained freely through the defect. The laminectomy incision was then carefully reapproximated using a continuous suture of 3-0 Dexon for the back muscles and a continuous 3-0 Prolene suture for skin closure. 


\section{Experimental animals}

\section{Early omental placement (3 hours)}

The 11 cats comprising this group had their spinal cords injured in an identical fashion to the control animals. Immediately following spinal cord trauma, the back muscles and skin overlying the laminectomy site were closed. Two and one-half hours after cord injury, a 2-3 inch longitudinal incision was made in the left lateral abdominal wall which was deepened into the peritoneal cavity with the cat in prone position. The omentum was lengthened into a pedicle using a previously reported technique in which the omentum is removed from the spleen and from its middle and distal attachments along the greater curvature of the stomach (Alday and Goldsmith, 1972) (Fig. 1). After completing the

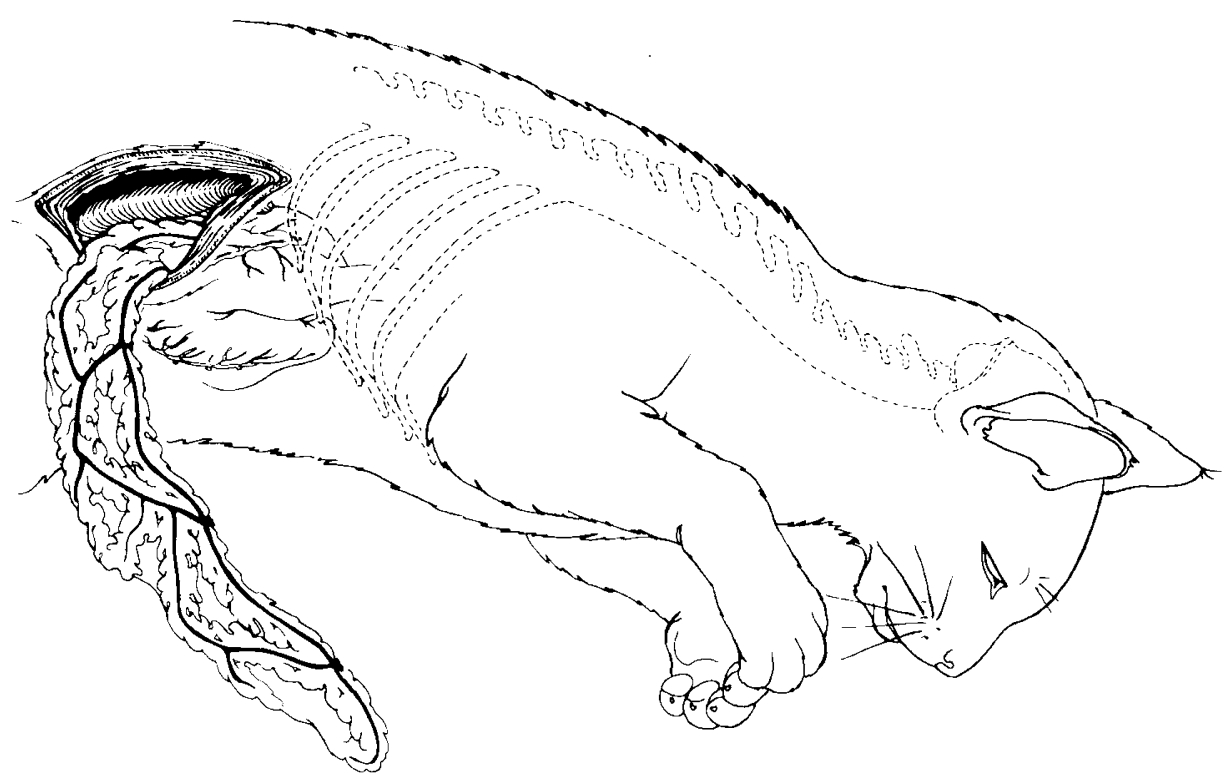

Figure 1. Lengthened omentum prior to subcutaneous placement.

surgical manoeuvres necessary to lengthen the omentum, the structure was brought out of the peritoneal cavity and placed in a subcutaneous tunnel connected to the laminectomy site (Fig. 2). The peritoneum was then closed snugly around the omental pedicle using a continuous 3-0 Dexon suture for peritoneal, muscle and fascial approximation and a continuous 3-0 Prolene suture for skin closure.

Exactly 3 hours after spinal cord injury, the skin and back muscles of these cats were separated and the dura and arachnoid overlying the injured cord 


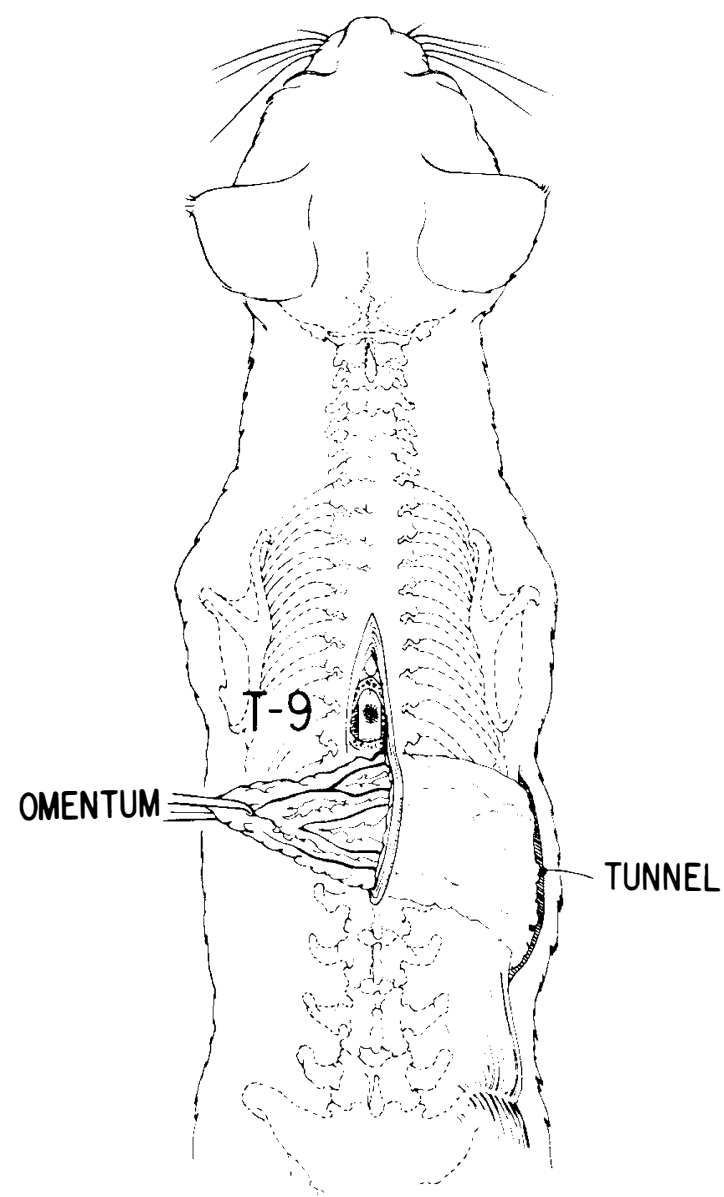

Figure 2. Omental application on site of injured spinal cord.

removed following which cerebrospinal fluid was observed. The lengthened omentum was then laid directly upon the underlying pial layer of the spinal cord. Several sutures were placed between the omentum and the cut edges of the dura in order to maintain close contact at the omental-spinal cord interface and to minimise any shearing effect at this junction. The back muscles and skin were then approximated over the laminectomy site in a fashion identical to the closure carried out in the control animals.

Late omental placement (6 and 8 hours)

Fourteen cats were divided into two equal groups and the omentum was placed on their spinal cord 6 and 8 hours, respectively, after injury. The surgical procedures on these cats were identical to the operations carried out on the cats who had omental placement 3 hours after spinal cord injury. 


\section{Results}

\section{(1) Control animals}

Motor function. Nine of the 11 cats comprising this group had paralysis of their hind legs which persisted up to the time of death 30 days after spinal cord injury. Of the two remaining cats in this control group, one could walk and the other push up on its hind legs but not ambulate at the time of sacrifice (Table 2).

Table 2 Compilation of functional and neuroelectrical data. Statistical difference between control and experimental functional levels: $\mathrm{P}<0.05$ using Mann-Whitney Test. Statistical differences of SEPs between groups. Left $-\mathrm{P}$ value $<0.005$; right $-\mathrm{P}$ value not statistically significant using Fisher's Exact Test.

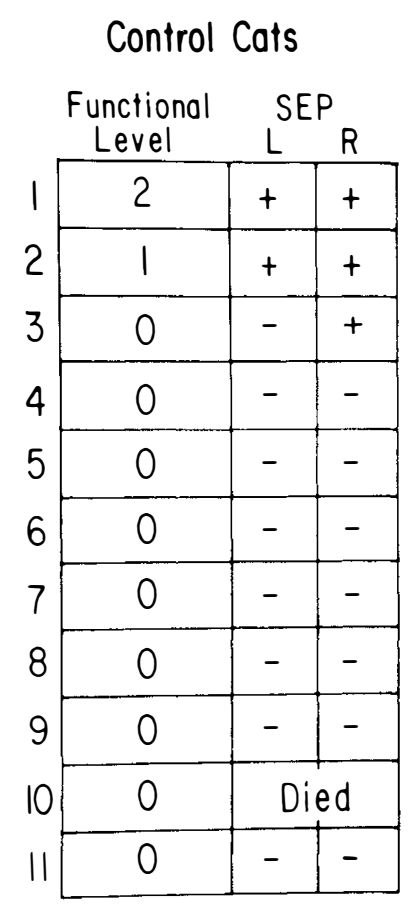

\section{Cats with Omental Protection}

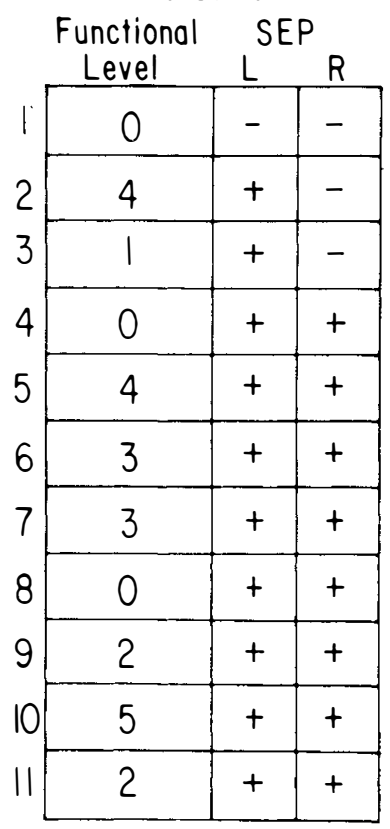

Somatosensory evoked potentials. One of the 11 cats in this group (\#10) did not have an SEP performed prior to sacrifice because it died from an inadvertent overdose of Ketalar anaesthesia administered just prior to the proposed SEP examination. The remaining 10 cats had their SEP performed on all extremities immediately prior to sacrifice. All front legs of the animals showed positive SEPs. The hind limbs of three cats showed positive SEPs in five of their six hind extremities. Four of these five positive SEPs were in the hind legs of the two control cats who had regained some degree of motor function. The fifth positive SEP was observed in a single limb of a paralysed cat. Seventyfive per cent of these control animals demonstrated absence of neuroelectrical activity from their back legs (Fig. 3). 


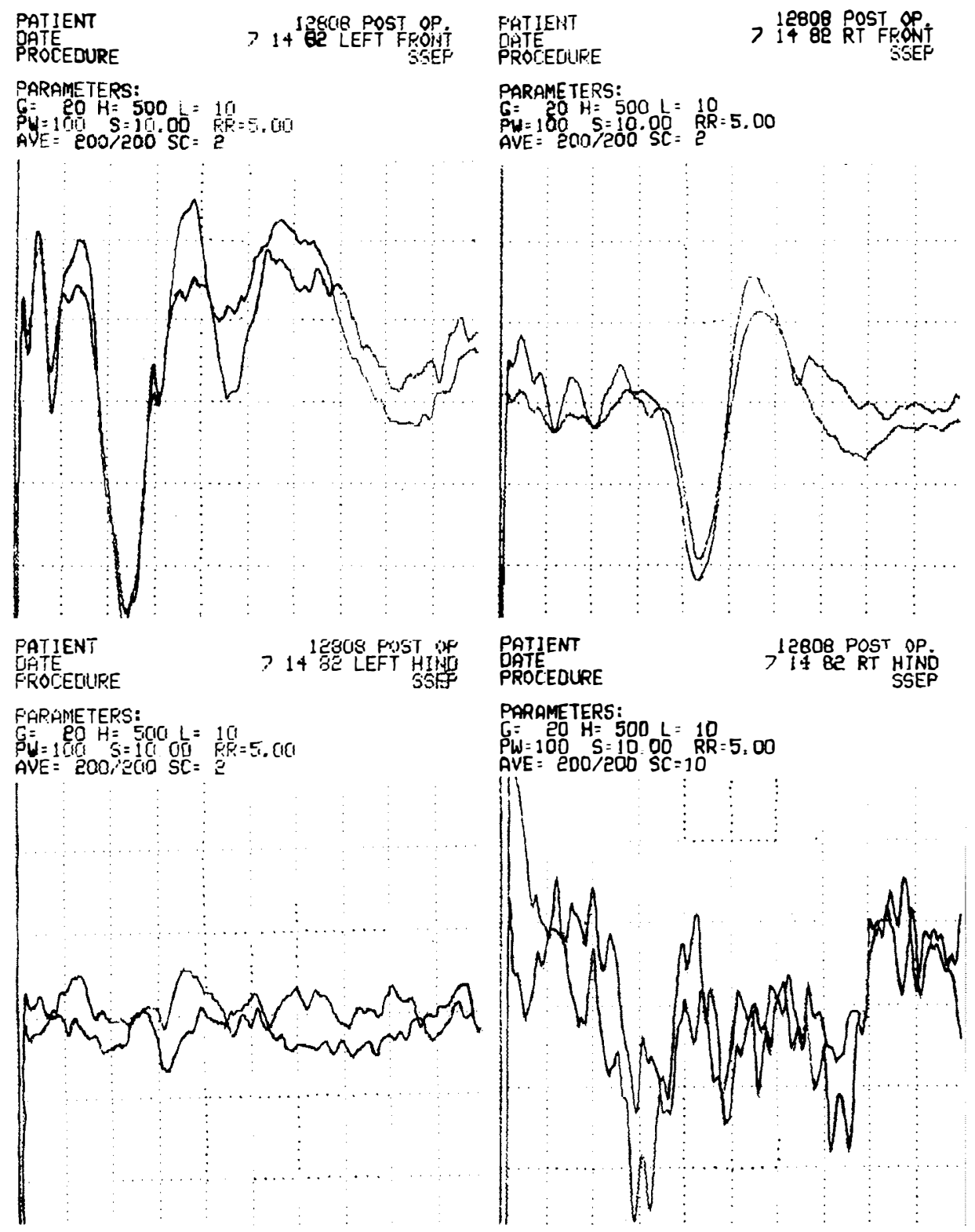

Figure 3. SEP of a representative cat without omental application. Stimulation pulses of 100 microseconds duration were generated at a rate of $5 \mathrm{stimuli} / \mathrm{second}$ with an analysis time of 100 milliseconds. SC (multiplication of gain) is 2 in left hind limb. Negative SEP persisted even with enhancement of SC to 10 as seen in right hind limb.

\section{(2) Experimental animals}

(a) Early omental placement (3 hours)

Motor function. Of the 11 cats comprising this group, five regained varying degrees of walking activity by the time of their death, 30 days after spinal cord 
injury. An additional two cats could push up on their hind legs but not ambulate. The remaining four cats in this series remained paralysed at their death 30 days after injury (Table 2).

Somatosensory evoked potentials. SEPs were performed on all extremities immediately prior to sacrifice 30 days after cord injury. All front limbs demon-

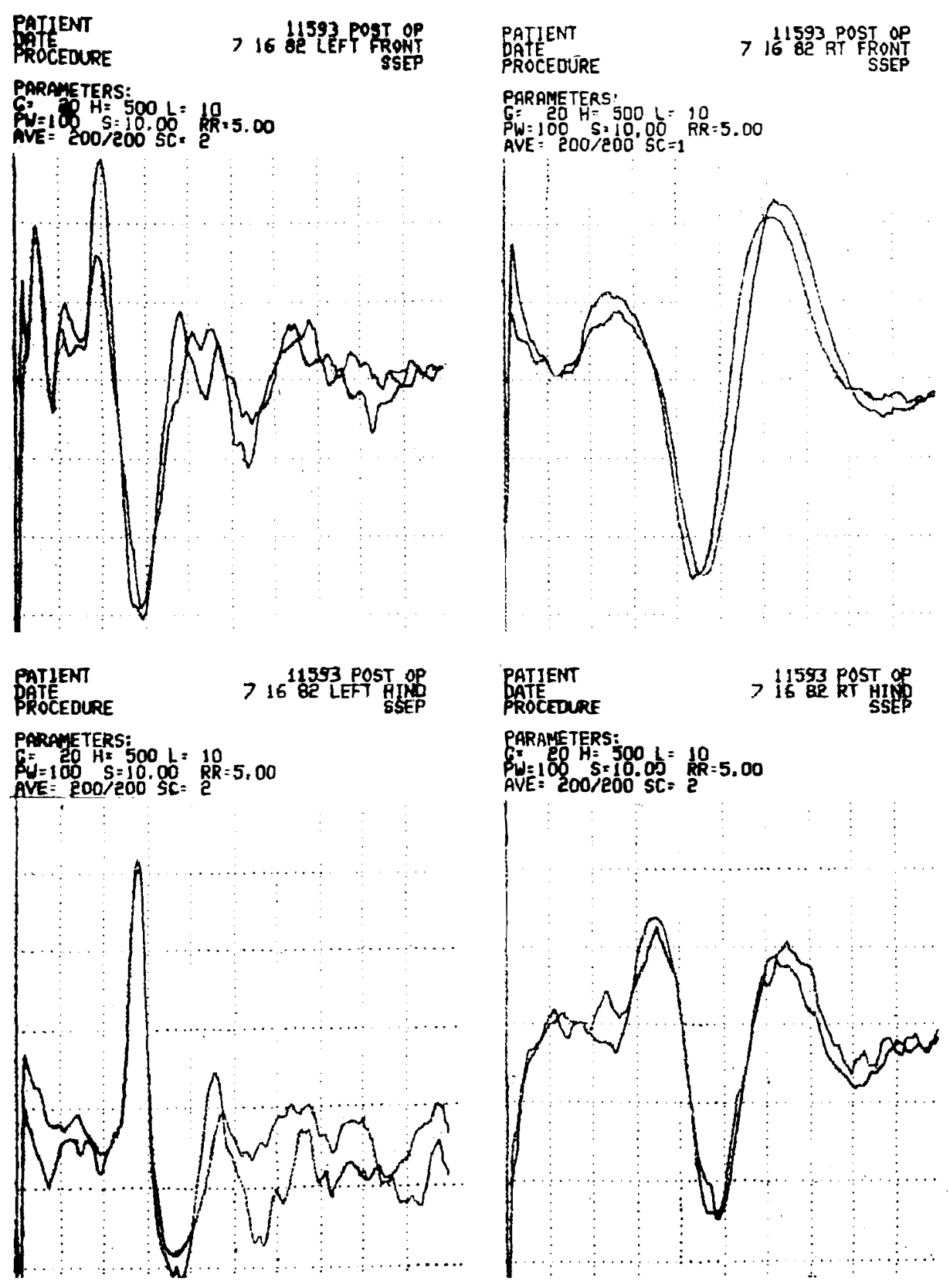

Figure 4. SEP of a representative cat with omental transposition. Positive SEP present in both hind limbs 30 days after spinal cord injury. 
strated positive SEPs. Of the 22 hind limbs, 18 showed positive SEPs; an 82 per cent incidence of neuroelectrical activity (Fig. 4).

\section{(b) Late omental placement (6 and 8 hours)}

Motor function. The 14 cats with late omental placement remained paralysed 30 days after spinal cord injury.

Somatosensory evoked potentials. The front limbs of the 14 cats all had positive SEPs. One of the seven cats with placement 6 hours following cord injury showed a positive SEP in a single hind leg at 30 days. The hind limbs of the remaining six cats with 6-hour omental placement had negative SEPs. The seven cats with omental placement 8 hours after spinal cord injury all had negative SEPs from their hind limbs at 30 days.

All cats with late omental application were allowed to live an extra two weeks to see if this added time would improve motor and/or neuroelectrical activity. These parameters remained unchanged from those observed at 30 days.

\section{Histology}

Longitudinal serial sections were taken at the level of spinal cord trauma with transverse sections being obtained from above and below the area of impact.

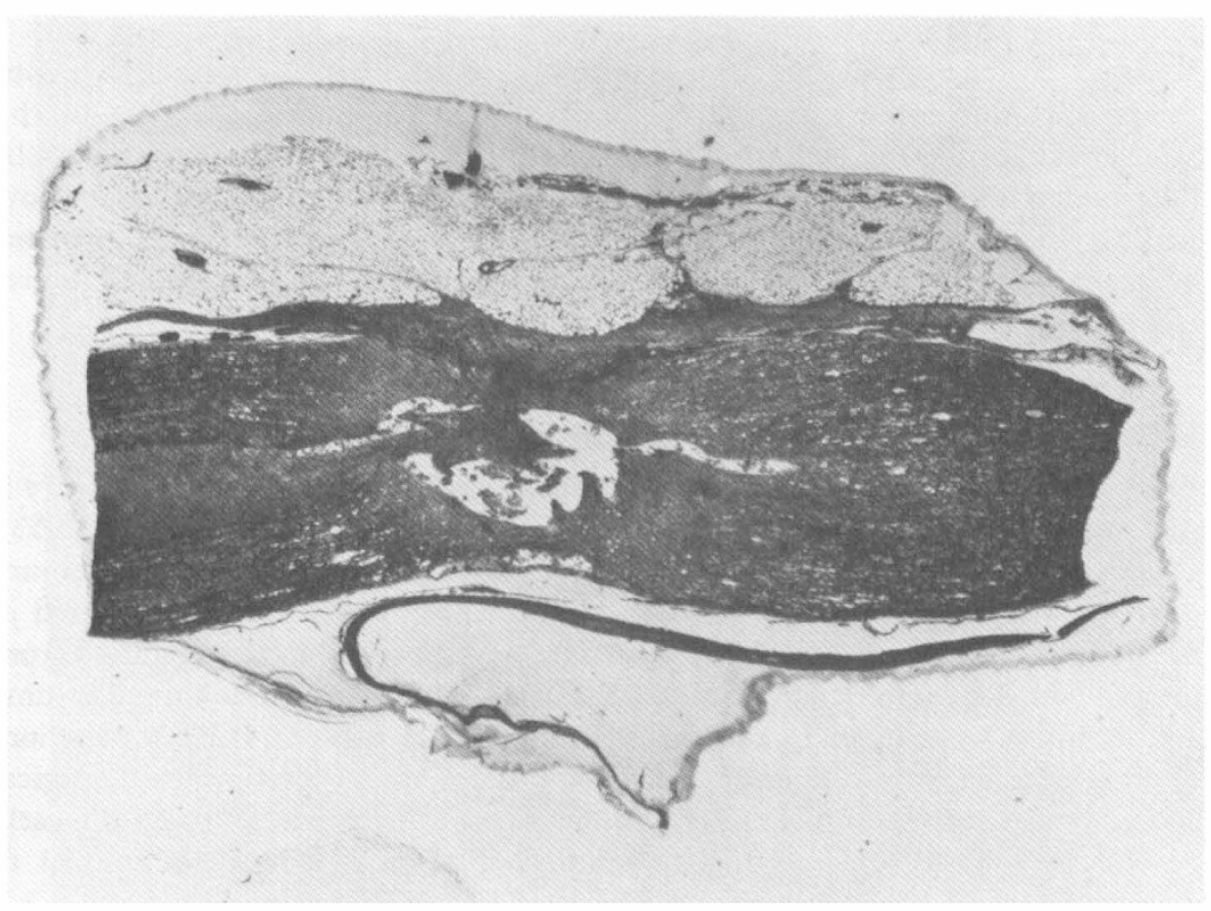

Figure 5. Spinal cord 30 days after injury showing intimite adherence of omentum on surface. Note severe injury within cord substance but lack of fibrosis. Cat had a Tarlov grade 4 with bilateral positive SEPs $(\times 12 \cdot 6, \mathrm{H} \& \mathrm{E})$. 


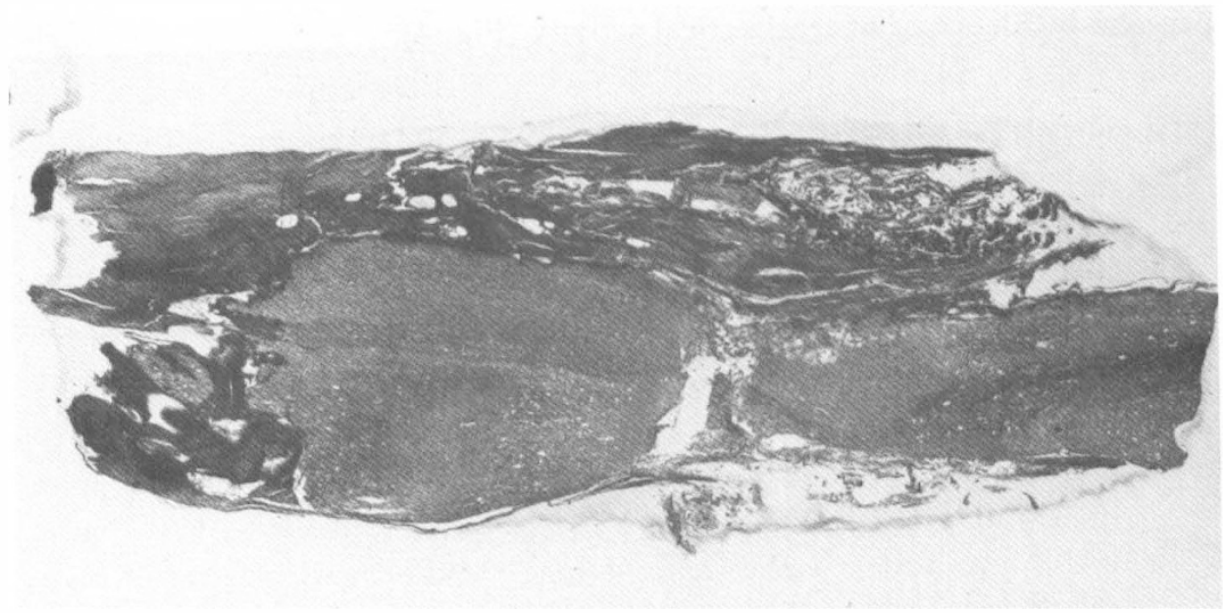

Figure 6. Spinal cord 30 days after injury without omental protection showing extensive scar formation with constriction at impact site. Cat had a Tarlov grade 0 with bilateral negative SEPs. $(\times 11 \cdot 4, \mathrm{H} \& \mathrm{E})$.

Tissue stains used were hematoxylin-eosin, Masson trichrome, hexatoxylin-van Gieson and Holmes silver stain.

Gross destruction of the spinal cords of the cats, with or without omental placement, was extensive (Figs. 5 and 6). The histological evidence of this severe tissue injury was demonstrated by cyst formation, vacuolisation, and myelin destruction. Descending tracts below the level of injury and ascending tracts above had varying degrees of degeneration. It was of interest that only a small number of intact myelinated axons were necessary for preservation of motor and neuroelectrical activity.

\section{Discussion}

Some investigators contend that the ultimate damage from spinal cord injury is determined from the moment of impact (Guttmann, 1973; Pennybacker, 1953). Observations made in our laboratory would strongly suggest that the final injury to the spinal cord involves two basic mechanisms: (1) tissue injury created in direct relationship to the force of impaction, and (2) tissue injury resulting from the cascade of pathobiological events that begin shortly after spinal cord trauma and within hours can lead to ischaemic hypoxia and eventual cord destruction. If there is to be improvement in the prognosis of spinal cord injuries, surgical and/or pharmacological techniques will have to be developed to lessen the early destructive physiological changes that occur, since it is beyond control to manipulate cord damage directly related to the force of an impact.

The omentum has the ability to produce blood vessels that make vascular connections to the pia mater of the normal spinal cord within 72 hours of omental transposition (Goldsmith et al., 1975; Levander and Zwetnow, 1978). We have 


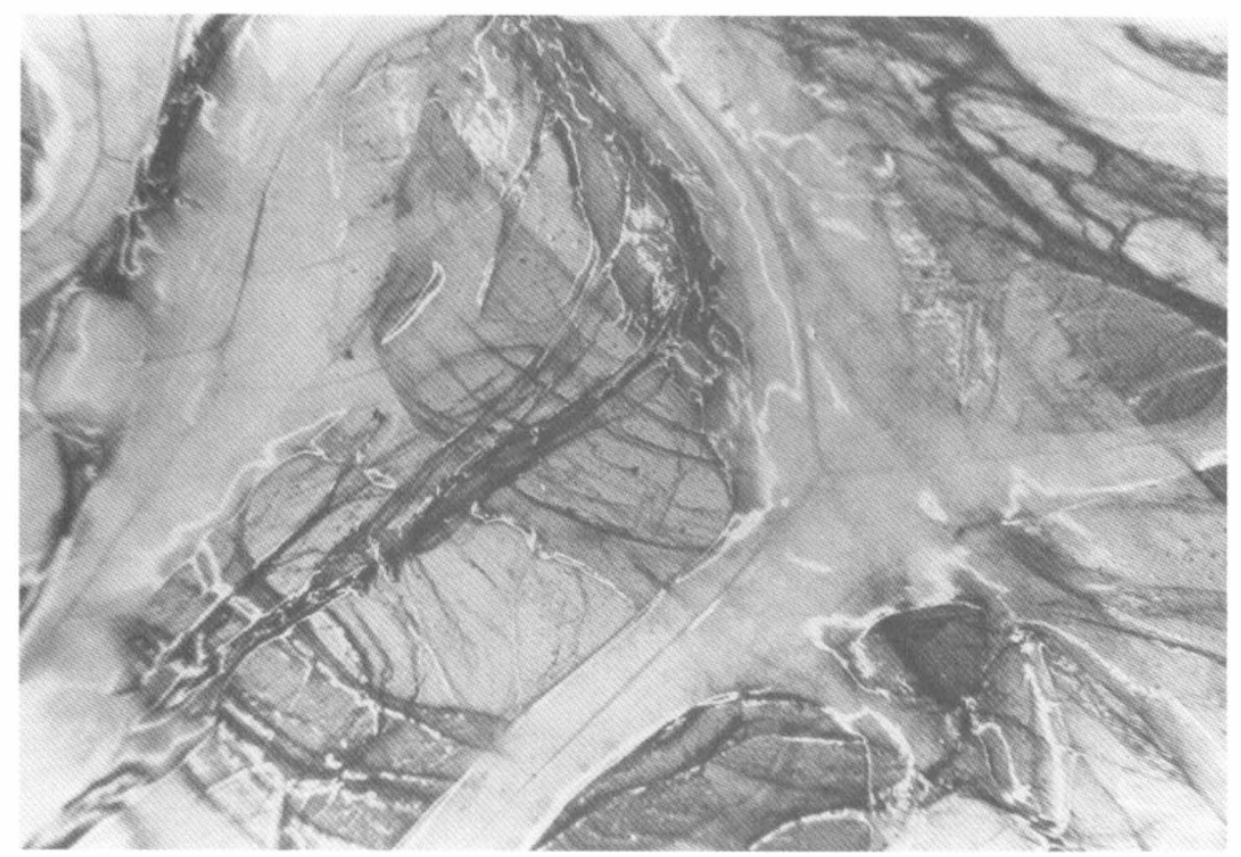

Figure 7. Omental tissue immersed in India ink for 30 seconds. Note India ink in omental lymphatics.

observed that vascularisation occurs at an even faster rate when the omentum is applied to a traumatised spinal cord. As important as this addition of a supplemental blood supply might prove in treating an injured spinal cord, the major influence of the omentum in such injuries appears to be its ability to markedly diminish post-traumatic oedema.

It had been shown clinically that the omentum can absorb oedema fluid from peripheral areas of the body (Goldsmith et al., 1967). A simple experiment to show the enormous absorptive capabilities of the intact omentum is to place a piece of pedicled omental tissue in a beaker filled with India ink and saline. Macromolecules of India ink solution will appear almost instantaneously within omental pathways (Fig. 7). This ability of the omentum for absorption has been shown to allow for the transport of 30 per cent of the entire cerebrospinal fluid reservoir through omental channels (Levander and Zwetnow, 1978). Absorption of this central nervous system exudate has been well observed by one of the authors (H.S.G.) following the performance of omental transposition to the brain or spinal cord in hundreds of animals and over a dozen humans over the past decade. Never in a single instance did a post-operative cerebrospinal fluid leak develop in spite of the arachnoid membrane being opened in every case. In fact, the senior author was recently asked to operate on a patient with a persistent cerebrospinal fluid fistula resulting from surgery and radiation required in the treatment of a malignant tumour of the back. Placing the intact omentum directly upon the spinal cord proved successful in arresting the cerebrospinal fluid fistula leak (Morain, 1983). 


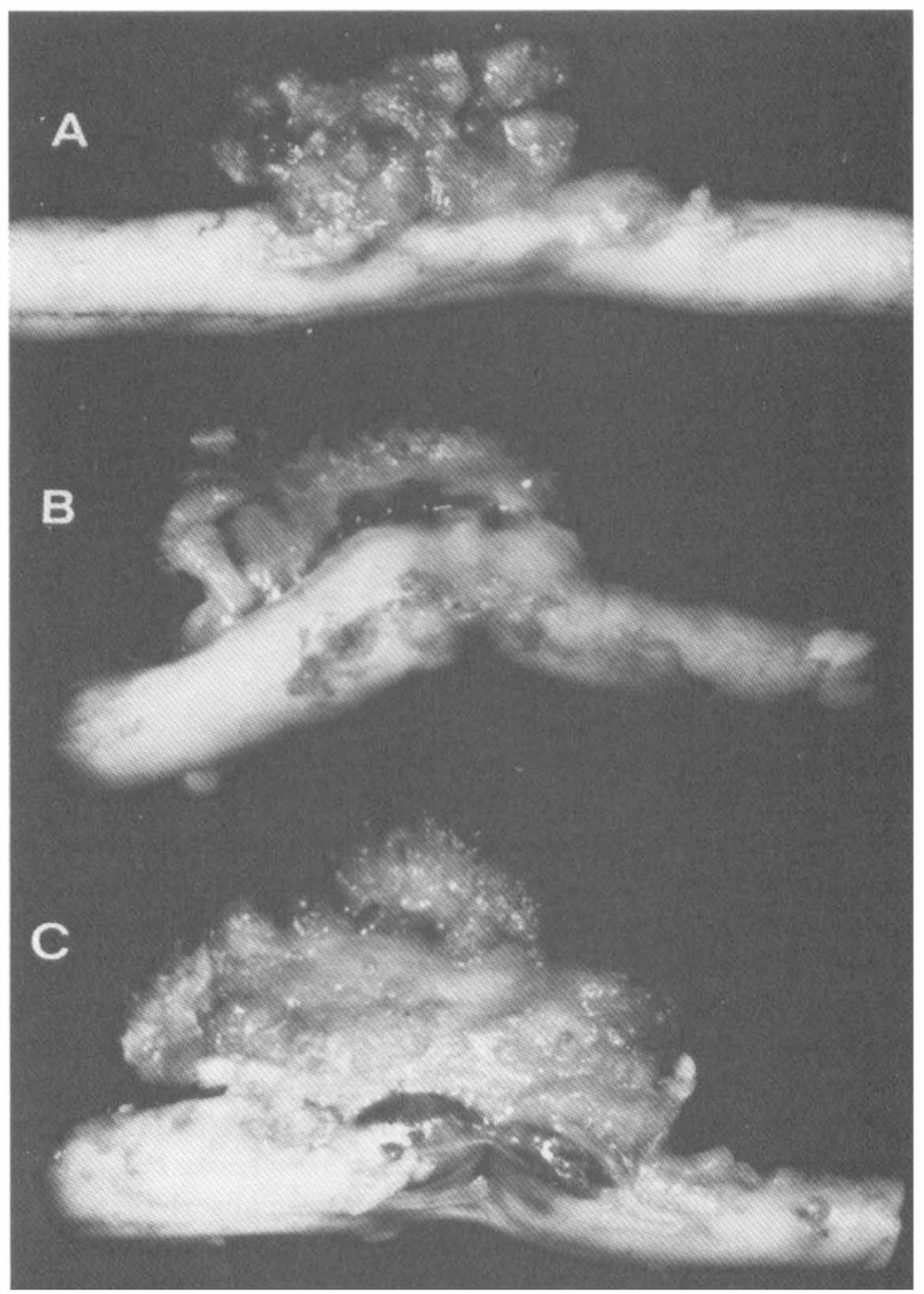

Figure 8. Spinal cord of cats 14 days after injury. (A) Omental transposition to injured cord demonstrating only minimal scar formation. (B) Post trauma laminectomy and dura removal over injury site. Note fluid accumulation between cord and overlying scar formation. (C) Post trauma myelotomy showing resolving haematoma. Of special interest is the early tendency for scar production (B \& C) which leads to an hourglass constriction previously reported (8).

Allen in 1914 was the first to describe a technique for lessening the deleterious effects of spinal cord injury by creating a median longitudinal incision (myelotomy) directly into the spinal cord 2 hours after injury with sacrifice of the animal 4 hours later (Allen, 1914). He reported that this procedure preserved spinal cord architecture because of 'outpouring of serum and blood from the substance of the injured cord which preserved the remaining cord substance.'

Allen's short-range protection of the spinal cord using a myelotomy precluded the unfavourable long-range effect of having oedema fluid persist over an 


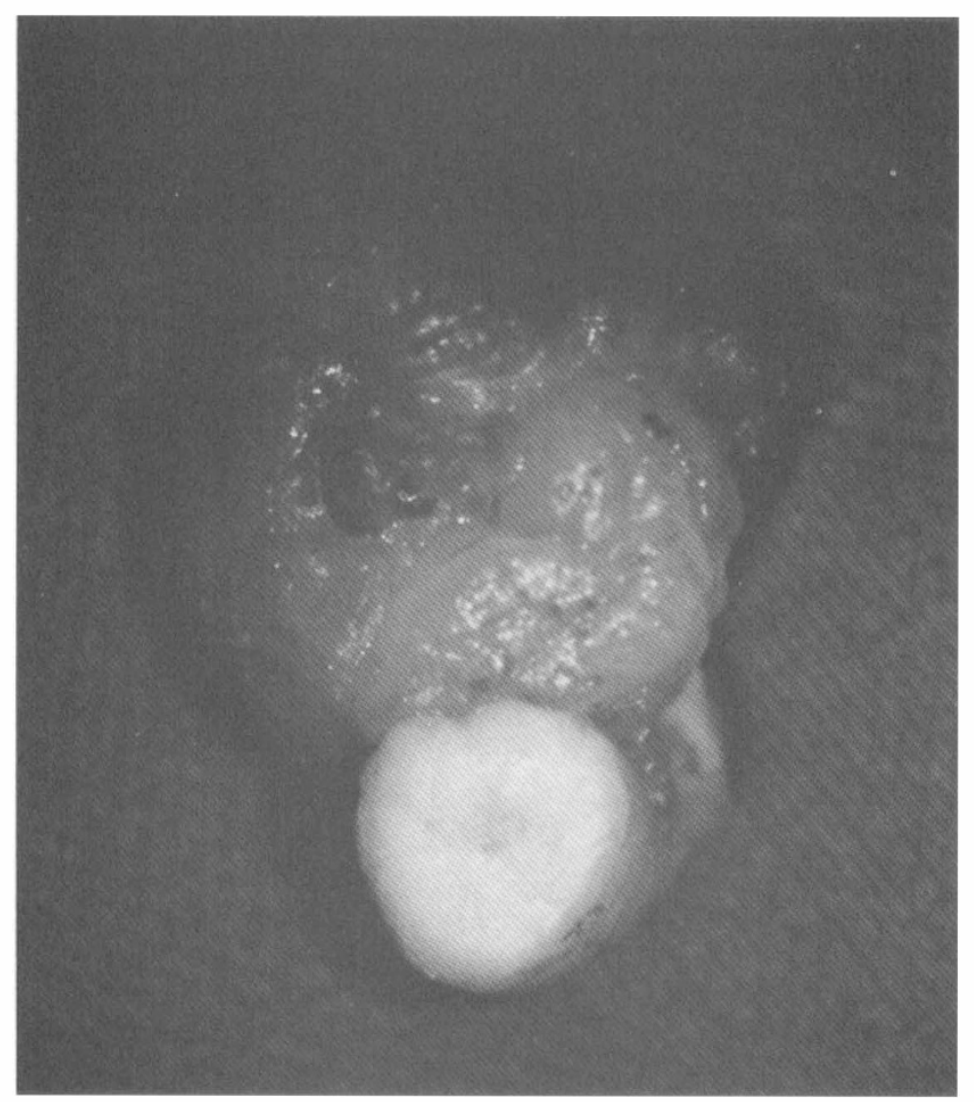

Figure 9. Cross section of $\mathrm{A}$ in Figure 8. Note close contact of omentum to spinal cord with apparent absence of oedema at omental/spinal cord interface.

extended period of time. Failure to absorb this vasogenic oedema following spinal cord trauma apparently causes an exaggerated fibrotic reaction which ultimately leads to spinal cord compression, cystic formation and angulation which is directly related to scar formation (Fig. 8).

The improved motor and neuroelectrical activity shown in this experiment after omental transposition to a recently injured spinal cord is theorised to result from the omentum's known ability to absorb oedema fluid. This absorptive effect conceivably leads to the development of a dynamic equilibrium between production of vasogenic oedema from the injured cord and its absorption by the omentum. If one examines the spinal cord of a cat 2 to 4 weeks after injury, an almost complete absence of oedema will be noted at the omental/spinal cord interface (Fig. 9); a phenomenon not seen in cats without omental application. The ability of the omentum to remove vasogenic oedema may well lessen the amount of fibrinogen and fibrin found in this fluid, thereby decreasing the foundation for fibroblast proliferation at the site of cord injury. 


\section{Résumé}

On a trouvé que le positionnement de l'épiploon intact sur une moëlle épinière récemment traumatisée était efficace pour réduire le dysfonctionnement moteur et neuro-électrique dans un groupe de chats. On a théorisé que l'effet bienfaisant de la transposition de l'épiploon était dû à l'établissement d'un équilibre dynamique entre la production d'oedème vasogène de la moëlle épinière blessée et son absorption à travers les passages épiplöques. On avance l'hypothèse que l'enlèvement de l'oedème vasogène à l'interface épiploon/moëlle épinière stabilise une pression de tissu augmentante à l'intérieur de la moëlle épinière pendant la phase aiguë de la blessure et qu'à une période ultérieure il réduit la formation de cicatrice à l'emplacement de la blessure.

\section{Zusammenfassung}

Man hat gefunden, dass die Positionierung des intakten Omentums auf einen neulich traumatisierten Rückengrat wirksam in der Verminderung der motorischen und der neuroelektrischen Dysfunktion in einer Gruppe Katzen ist. Man hat die Theorie vorgeschlagen, dass die heilsame Wirkung der omentalen Transposition der Schaffung eines dynamischen Gleichgewichts zwischen der Erzeugung von vasogenischem Ödem vom verletzten Rückengrat und seiner Absorption durch die omentalen Wege zuzuschreiben ist. Die Entfernung des vasogenischen Ödems an der Zwischenfläche Omentum/ Rückengrat könnte, wie man als Hypothese vorschlägt, einen steigenden Gewebedruck innerhalb des Rückengrats während der akuten Phase der Verletzung stabilisieren, und an einem späteren Zeitpunkt die Narbenbildung an der Verletzungsstelle vermindern.

\section{References}

Alday ES, Goldsmith HS 1970 Surgical technique for omental lengthening based on arterial anatomy. Surgery, Gynecology, and Obstetrics 135:103-107.

AlLEN AR 1911 Surgery of experimental lesion of spinal cord equivalent to crush injury of fracture-dislocation of spinal cord. Journal of the American Medical Association 57: 878-880.

Allen AR 1914 Remarks on the histological changes in the spinal cord due to impact: An experimental study. Journal of Neurological and Mental Diseases 141-147.

Goldsmith HS, De Los SAntos R, BeAtTie EJ 1967 The relief of chronic lymphedema by omental transposition. Annals of Surgery 166:573-585.

Goldsmith HS, Duckett S, Chen WF 1975 Spinal cord vascularization by intact omentum American Journal of Surgery 129:262-265.

Goldsmith HS, Steward E, Chen WF, Duckett S 1983 Application of intact omentum to the normal and traumatized spinal cord. In: Kao CC, Bunge RP, Reir RJ (eds) Spinal cord reconstruction, Raven Press, New York.

Guttmann L 1973 Spinal cord injuries. In: Comprehensive management and research, Blackwell Scientific Publications, Oxford, London, Edinburgh and Melbourne, p 122-157.

LEVANDER B, ZWETNOW NN 1978 Bulk flow of C.S.F. through a lumbo-omental pedicle graft in the dog. Acta Neurochirurgica 41:147-155.

MORAIN WD 1983 Flaps of the latissimus dorsi muscle in difficult wounds of the trunk and arm. American Journal of Surgery 145:520-525.

PenNyBACKER JB 1953 The treatment of traumatic paraplegia. Journal of Bone and Joint Surgery 358:517-518.

TARLOV IM 1957 Spinal cord compression: Mechanism of paralysis and treatment, Charles C. Thomas, Springfield, IL. 